JOURNAL of

MAINE MEDICAL CENTER Journal of Maine Medical Center

Volume 4

Issue 1 Winter 2022

Article 11

2022

\title{
A Descriptive Analysis of Patient Demographics at a Sports Medicine Clinic During the COVID-19 Pandemic
}

\author{
William S. Douglas \\ Maine Medical Center
}

Et al.

Follow this and additional works at: https://knowledgeconnection.mainehealth.org/jmmc

Part of the Other Public Health Commons, Race and Ethnicity Commons, and the Sports Medicine Commons

\section{Recommended Citation}

Douglas, William S.; Dexter, Williams; Haskins, Amy PhD; and Holt, Christina (2022) "A Descriptive Analysis of Patient Demographics at a Sports Medicine Clinic During the COVID-19 Pandemic," Journal of Maine Medical Center. Vol. 4 : Iss. 1 , Article 11.

Available at: https://knowledgeconnection.mainehealth.org/jmmc/vol4/iss1/11 https://doi.org/10.46804/ 2641-2225.1103

The views and thoughts expressed in this manuscript belong solely to the author[s] and do not reflect the opinions of the Journal of Maine Medical Center or MaineHealth.

This Research and Quality Improvement Brief is brought to you for free and open access by Maine Medical Center Department of Medical Education. It has been accepted for inclusion in the Journal of Maine Medical Center by an authorized editor of the MaineHealth Knowledge Connection. For more information, please contact Dina McKelvy mckeld1@mmc.org.

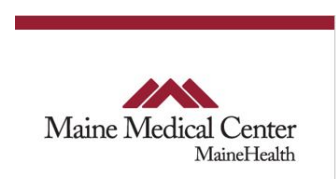




\section{A Descriptive Analysis of Patient Demographics at a Sports Medicine Clinic During the COVID-19 Pandemic}

Authors

William S. Douglas, Williams Dexter, Amy Haskins PhD, and Christina Holt 


\title{
A Descriptive Analysis of Patient Demographics at a Sports Medicine Clinic During the COVID-19 Pandemic
}

\author{
William Douglas, DO,${ }^{1}$ William Dexter, MD,${ }^{1}$ Amy Haskins, $\mathrm{PhD},{ }^{1}$ Christina Holt, MD ${ }^{1}$ \\ ${ }^{1}$ Maine Medical Center, Departments of Sports Medicine and Family Medicine, Portland, ME
}

Keywords: race factors, COVID-19, sports medicine, access to health care, health care disparities

T he COVID-19 pandemic has disrupted the health care system in the United States and highlighted underlying social and racial injustices and inequities that plague it. In the United States, Black, Indigenous, and people of color (BIPOC) are more likely to become infected, hospitalized, or die from COVID-19 than White people. ${ }^{1,2,3}$ Nowhere has this been more apparent than in Maine, a state where $1.42 \%$ of the population identifies as Black, and $94.25 \%$ of the population identifies as White. ${ }^{4}$ Yet, during the summer of 2020, Maine's Black population accounted for $22 \%$ of the state's COVID-19 cases, whereas Maine's White population accounted for $66.8 \%$ of total cases. ${ }^{5}$ Members of BIPOC communities have historically faced reduced quality of care versus White communities. ${ }^{6}$ Furthermore, the pandemic has exacerbated these underlying health care disparities. ${ }^{7}$ One study even suggested that BIPOC patients' access to outpatient care has been lower than that of White patients. ${ }^{8}$ Given the disparate burden of COVID-19 on the BIPOC community in Maine, we sought to understand the demographic makeup and assess unequal racial and ethnic representation of the outpatient population in our sports medicine clinic during the 2020 COVID-19 pandemic.

\section{METHODS}

We collected demographic data on all patients who visited the Maine Medical Partners Orthopedics and Sports Medicine outpatient clinics in South Portland, Maine, for two 3-month periods: the summer before the COVID-19 pandemic (July 1, 2019 to September

Correspondence: William Douglas, DO

Department of Sports Medicine, Maine Medical Center Portland, ME

wsdouglas@gmail.com
30, 2019) and the summer of 2020 (July 1, 2020 to September 30, 2020). Information obtained included race, ethnicity, marital status, sex, age, employment status, type(s) of insurance, preferred language, and 'interpreter needed' status. Chisquare tests were used to retrospectively compare patient characteristics between the 2 time periods. Primary outcomes included significant differences in race and ethnicity representation between the 2 time periods. Secondary outcomes included changes in all other demographic information. Demographic data used for this study was collected from self-identified information in standard patient intake forms uploaded into the electronic medical record. This study received IRB exemption from Maine Medical Center.

\section{RESULTS}

During the 2 time periods, the racial breakdown of patients did not significantly differ. White patients accounted for most patients seen in the 2019 $(91.2 \%, \mathrm{n}=2672)$ and 2020 timeframe $(90.3 \%, \mathrm{n}=$ 2425) $(P=.25$; Table 1$)$. The proportion of BIPOC patients was similar between $2019(7.4 \%, \mathrm{n}=198)$ and $2020(7.8 \%, \mathrm{n}=189)(P=.25)$. Regarding ethnicity, the proportion of Hispanic patients increased significantly from $1.1 \%(n=30)$ in 2019 to $2.0 \%(\mathrm{n}=48)$ in $2020(P=.01)$.

Mean age was similar between the 2 time periods (49.5 years in 2019, and 50.6 years in 2020; $P=$ .07 However, between the 2 time periods, the percentage of 0 - to 9-year-old patients increased $(1.9 \%$ in 2019 vs $2.4 \%$ in $2020, P=.007)$; the percentage of 66- to 79-year-old patients increased ( $20.7 \%$ in 2019 vs $23.5 \%$ in $2020, P=.007$ ); and the proportion of 10- to 17-year-old patients decreased $(9.1 \%$ in 2019 vs $6.9 \%$ in $2020, P=.007)$. 
Table 1. Demographic Data

\begin{tabular}{|c|c|c|c|}
\hline Variables & $\begin{array}{l}\text { July-September } 2019 \\
\text { (n= 2672) }\end{array}$ & $\begin{array}{l}\text { July-September } 2020 \\
\text { (n= 2425) }\end{array}$ & $P$ value \\
\hline \multicolumn{4}{|l|}{ Sex. No. (\%) } \\
\hline Female & $1402(52.5)$ & $1250(51.5)$ & \multirow{2}{*}{0.51} \\
\hline Male & 1270 (47.5) & 1175 (48.5) & \\
\hline \multicolumn{4}{|l|}{ Age, y, No. (\%) } \\
\hline $0-9$ & 52 (1.9) & $59(2.4)$ & \multirow{5}{*}{0.007} \\
\hline $10-17$ & 242 (9.1) & $168(6.9)$ & \\
\hline $18-65$ & $1698(63.5)$ & $1528(63.0)$ & \\
\hline $66-79$ & $553(20.7)$ & 569 (23.5) & \\
\hline $80+$ & $127(4.8)$ & $101(4.2)$ & \\
\hline \multicolumn{4}{|l|}{ Race, No. (\%) } \\
\hline Black or African American & 109 (4.1) & $93(3.8)$ & \multirow{4}{*}{0.25} \\
\hline Other & 89 (3.3) & $96(4.0)$ & \\
\hline Unknown/Refused & 36 (1.3) & 46 (1.9) & \\
\hline White or Caucasian & $2438(91.2)$ & $2190(90.3)$ & \\
\hline \multicolumn{4}{|l|}{ Ethnicity, No. (\%) } \\
\hline Hispanic & $30(1.1)$ & $48(2.0)$ & \multirow{3}{*}{0.02} \\
\hline Non-Hispanic & 2605 (97.5) & $2332(96.2)$ & \\
\hline Unknown/Refused & $37(1.4)$ & $45(1.9)$ & \\
\hline \multicolumn{4}{|l|}{ Language, No. (\%) } \\
\hline English & 2542 (95.2) & $2331(96.1)$ & \multirow{2}{*}{0.12} \\
\hline Other & $127(4.8)$ & $94(3.9)$ & \\
\hline \multicolumn{4}{|l|}{ Interpreter needed, No. (\%) } \\
\hline Yes & $92(3.4)$ & $72(3.0)$ & \multirow{3}{*}{0.34} \\
\hline No & $2580(96.6)$ & $2353(97.0)$ & \\
\hline \multicolumn{3}{|l|}{ Insurance, No. (\%) } & \\
\hline Commercial & |1506 (56.4) & $1328(54.8)$ & \multirow{5}{*}{0.03} \\
\hline Medicaid & $272(10.2)$ & $274(11.3)$ & \\
\hline Medicare & |716 (26.8) & $664(27.4)$ & \\
\hline Other government plan & $60(2.2)$ & $78(3.2)$ & \\
\hline None & $118(4.4)$ & $81(3.3)$ & \\
\hline \multicolumn{4}{|l|}{ Marital status, No. (\%) } \\
\hline Married/Domestic partner & |1366 (51.1) & $1324(54.6)$ & \multirow{5}{*}{0.11} \\
\hline Single & $966(36.2)$ & $803(33.1)$ & \\
\hline Divorced/Legally separated & 194 (7.3) & $180(7.4)$ & \\
\hline Widowed & 129 (4.8) & $102(4.2)$ & \\
\hline Unknown/refused & $17(0.6)$ & $16(0.7)$ & \\
\hline \multicolumn{4}{|l|}{ Employment status, No. (\%) } \\
\hline Employed (full, part, self) & $1270(47.6)$ & $1262(52.0)$ & \multirow{5}{*}{0.008} \\
\hline Retired & |616 (23.1) & 531 (21.9) & \\
\hline Disability & $151(5.6)$ & $123(5.1)$ & \\
\hline Student & 101 (3.8) & $63(2.6)$ & \\
\hline Not employed & $533(20)$ & 446 (18.4) & \\
\hline
\end{tabular}

Insurance carriers varied as well, with a greater percentage of Medicaid, Medicare, and "other government" insurances $(39.2 \%$ in 2019 vs $41.9 \%$ in $2020, P=.03$ ), and fewer commercial carriers (56.4\% in 2019 vs $54.8 \%$ in $2020, P=.03$ ). Concerning employment, the percentage of fulltime workers increased significantly from $34.0 \%$ (2019) to $37.2 \%(2020)(P=.03)$. The percentage of people with a disability dropped from $5.6 \%$ to $5.1 \%$, and those who were unemployed dropped from $20 \%$ to $18.4 \%(P=.03)$.
No statistical change occurred regarding the need for an interpreter, language spoken, or marital status between the 2 time periods.

\section{DISCUSSION}

Our retrospective analysis showed that representation of BIPOC patients in our outpatient sports medicine clinic did not decrease during the COVID-19 pandemic. In fact, our analysis showed a significant increase in the proportion of patients identifying as Hispanic. 
These results are reassuring in that, at least in our clinic population, racial representation was not affected during the COVID-19 pandemic. To our knowledge, there are no other studies that directly assess racial/ethnic demographic representation in outpatient clinics during the COVID 19 pandemic.

The significant decrease in the proportion of privately insured patients in our clinic during the pandemic is consistent with findings from another study. Specifically, Whaley et. al showed decreased use of elective care health services by the privately insured during the initial phases of the pandemic. ${ }^{9}$ However, unlike in our study, we did not find studies that directly compared demographic representation of privately versus publicly insured patients during the COVID-19 pandemic. Of note, the decreased proportion of 10- to 17-year-old patients during the pandemic may be attributed to reduced organized and community sports, which resulted in fewer opportunities for injury.

Limitations of this study include the potential lack of generalizability of our findings given the low baseline proportion of BIPOC patients in our study population. They also include inherent limitations of self-identified demographic data in our electronic health record.

\section{CONCLUSIONS}

Despite well-documented disparities in general regarding access to health care, as well as the unequal impact of COVID-19 on BIPOC communities in Maine and across the nation, we did not detect reduced representation of BIPOC patients in our outpatient sports medicine clinic during the 2020 COVID-19 pandemic.

\section{Conflicts of Interest: None}

\section{REFERENCES}

1. COVID-19 in racial and ethnic minority groups. Centers for Disease Control and Prevention. July 2020. Accessed November 1, 2020. https://www.cdc.gov/coronavirus/2019-ncov/

2. Gross CP, Essien UR, Pasha S, Gross JR, Wang S-Y, NunezSmith M. Racial and ethnic disparities in population-level Covid-19 mortality. J Gen Intern Med. 2020;35(10):3097-3099. doi:10.1007/s11606-020-06081-w

3. Cooper LA, Williams DR. Excess deaths from COVID-19, community bereavement, and restorative justice for communities of color. JAMA. 2020;324(15):1491-1492. doi:10.1001/ jama.2020.19567

4. Quick facts - Maine, 2019. United States Census Bureau. July 1, 2019. Accessed November 1, 2020. https://www.census.gov/ quickfacts/ME

5. COVID-19: Maine data. Maine Center for Disease Control \& Prevention. July 2020. Accessed November 1, 2020. https:// maine.gov/dhhs/mecdc/infectious-disease/epi/airborne/ coronavirus/data.shtml

6. COVID-19: health equity considerations and racial and ethnic minority groups. Centers for Disease Control and Prevention. Accessed September 26, 2020. https://www.cdc.gov/ coronavirus/2019-ncov/community/health-equity/race-ethnicity. html\#print

7. Abedi V, Olulana O, Avula V, et al. Racial, economic, and health inequality and COVID-19 infection in the United States. $J$ Racial Ethn Health Disparities. 2021;8(3):732-742. doi:10.1007/ s40615-020-00833-4

8. Leuchter RK, Villaflores CWA, Norris KC, Sorensen A, Vangala $\mathrm{S}$, Sarkisian CA. Racial disparities in potentially avoidable hospitalizations during the COVID-19 pandemic. Am J Prev Med. 2021;61(2):235-239. doi:10.1016/j.amepre.2021.01.036.

9. Whaley CM, Pera MF, Cantor J, et al. Changes in health services use among commercially insured US populations during the COVID-19 pandemic. JAMA Netw Open. 2020;3(11):e2024984. doi: 10.1001/jamanetworkopen.2020.24984 